E3S Web of Conferences 1, 11005 (2013)

DOI: $10.1051 / \mathrm{e} 3$ sconf/20130111005

(c) Owned by the authors, published by EDP Sciences, 2013

\title{
Mercury bioaccumulation in the Mediterranean
}

\author{
S. Cinnirella, ${ }^{1}$ N. Pirrone, ${ }^{2}$ M. Horvat, ${ }^{3}$ D. Kocman ${ }^{3}$ and J. Kotnik ${ }^{3}$ \\ ${ }^{1}$ CNR-Institute of Atmospheric Pollution Research, Division of Rende, Rende, Italy, s.cinnirella@iia.cnr.it \\ ${ }^{2}$ CNR-Institute of Atmospheric Pollution Research, Monterotondo Scalo, Italy \\ ${ }^{3}$ Jožef Stefan Institute, Ljubljana, Slovenia
}

\begin{abstract}
This study details mercury pollution within the food chain of the Mediterranean by analysing the most comprehensive mercury dataset available for biota and water measurements. In this study we computed a bioaccumulation factor (BAF) for datasets in the existing mercury-related scientific literature, in on-going programs, and in past measurement campaigns. Preliminary results indicate a major lack of information, making the outcome of any assessment very uncertain. Importantly, not all marine eco-regions are (or have ever been) covered by measurement campaigns. Most lacking is information associated with the South-Eastern part of the Mediterranean, and in several eco-regions it is still impossible to reconstruct a trophic net, as the required species were not accounted for when mercury measurements were taken. The datasets also have additional temporal sampling problems, as species were often not sampled systematically (but only sporadically during any given sampling period). Moreover, datasets composed of mercury concentrations in water also suffer from similar geographic limitations, as they are concentrated in the North-Western Mediterranean. Despite these concerns, we found a very clear bioaccumulation trend in 1999, the only year where comprehensive information on both methylmercury concentrations in water and biota was available.
\end{abstract}

Key words: heavy metals, marine eco-regions, food web, mercury pollution, trophic level

\section{Introduction}

Studies carried out during the 1970s indicated elevated mercury concentrations in Mediterranean fish. Mercury concentrations in these fish were twice that found for the same species living in the Atlantic Ocean (Thibaud 1971, Bernhard and Renzoni 1977). More recent results have confirmed these findings (MERLUMED project: www.ifremer.fr/medicis/ EN/projets/merlumed.html).

This occurrence of higher metal bioaccumulation in planktonic organisms in oligotrophic environments suggests that the "Med-Hg anomaly" ought to originate at the base of the food chain, from higher bioaccumulation levels of monomethyl mercury $(\mathrm{MeHg})$ in phytoplankton and bacterioplankton (Chen et al., 2008; Harmelin-Vivien et al., 2009). The evidence that $\mathrm{MeHg}$ biomagnifies along pelagic food chains has been widely accepted, yet the mechanisms regulating the formation of $\mathrm{MeHg}$, its initial incorporation at the base of pelagic food chains, and its subsequent trophic transfer remain controversial. Moreover, there exists a difference in background levels of several metals between the western and eastern parts of the Mediterranean, a fact that could be attributed to the
Alpic Orogenesis (alpine mountain range creation) and persistent volcanic activity in the South Aegean Sea (Law et al., 2010).

However, no detailed, regional-level assessments have been conducted that might establish the bioaccumulative impacts of mercury pollution within the food chain, especially as these impacts may vary across different Mediterranean eco-regions. This study gives details on mercury's distribution within the waters and biota of the food chain by analysing the most comprehensive mercury datasets available.

\section{Materials and Methods}

To assess mercury bioaccumulation in the Mediterranean, we collected datasets on mercury in biota and water. These include:

- MEDPOL, a dataset collected under the scientific and technical components of the Mediterranean Action Plan/Barcelona Convention. This dataset holds data and information on contaminant levels in different marine matrices;

- $\quad$ MLI, a dataset comprised of scientific publications 
that was collected by the Jožef Stefan Institute and refined at Institute of Atmospheric Pollution Research. This dataset holds information on mercury in different marine matrices, and, where possible, has been geo-located;

- RNO, the dataset established for the chemical surveillance of the French coastal zone;

- $\quad$ SIDIMAR, the dataset established for the chemical surveillance of the Italian coastal zone;

- $\quad$ and MERCYMS, a dataset composed of mercury measurements in marine waters collected during several cruises.

Once collected, all datasets were checked over to detect discrepancies between location and geographical coordinates. As most data was obtained from existing scientific literature, to the extent possible, this data was placed on the map according to the information available. Afterward, trophic levels (TLs) were associated with each organism by using Sealifebase (www.sealifebase.org), and each record was given a marine ecoregion.

The bioaccumulation of methylmercury in marine organisms is a complex process affected by many site-specific environmental factors. To establish bioaccumulation in the food chain we adopted the methodology proposed by Sanborn and Brodberg (2006). A bioaccumulation factor (BAF) can be computed from the following:

$$
B A F=\frac{\mathrm{Hg}_{\text {fish }}}{\operatorname{Hg}_{\text {water }}}\left[l \cdot \mathrm{kg}^{-1}\right]
$$

where $\mathrm{Hg}_{\text {fish }}$ is mercury concentration in fish and $\mathrm{Hg}_{\text {water }}$ the concentration of mercury in water.

BAFs are used to calculate aqueous concentration limits for total mercury, which would then be used to allocate mercury loading among various point and nonpoint sources, thereby guiding regulatory actions.

BAFs are site-specific, but when based on methylmercury they did not vary as a function of $\mathrm{HgT}$. We then completed a similar exercise for the greater Mediterranean by considering different methylmercury concentrations in both trophic levels and in water.

\section{Results and Discussion}

The global dataset is characterized by 12,736 values of total mercury (HgT) and 412 data of methylmercury $(\mathrm{MeHg})$ in biota. Most of data are limited to several key eco-regions (Figure 1). Data span the 1960-2010 time period, and include species that range from crustaceans to mammals. This wide variance of data enabled the identification of a few benthonic and pelagic food chains. For example, we detected the following trophic nets (Table 1).

For each species, we collected ancillary data: latitude, longitude, name of species, length, weight, trophic level, tissue, mean mercury concentration, mercury species, year of collection, and reference. When it was available, we also included minimum, maximum, and standard deviation of mercury concentrations.

Preliminary results indicated series limitations to the data, making any assessment very uncertain (Table 2). Not all marine eco-regions are represented by data. Most lacking was data from the South-Eastern part of the Mediterranean. In addition, it was impossible to reconstruct a trophic net in several eco-regions, as the required species were not sampled in the measurement campaigns. Finally, the data examined had additional temporal limitations, as each species was often only sampled once during any given period.

Table 1. Main trophic nets in the Mediterranean, where mercury in tissues is available.

\begin{tabular}{|c|c|c|}
\hline Species & Main prey & $\begin{array}{l}\text { Trophic } \\
\text { Level }\end{array}$ \\
\hline a) & \multirow{6}{*}{$\begin{array}{l}\text { Cephalopods - T. sagittatus } \\
\text { Mainly animals (TL 2,8 and up) } \\
\text { - C. harengus }\end{array}$} & \\
\hline $\mathrm{X}$. gladius & & 4.50 \\
\hline T. sagittatus & & 4.01 \\
\hline C. harengus & & 3.23 \\
\hline Copepoda & & $? ? ?$ \\
\hline Benthic algae & & 1 \\
\hline b) & \multirow{4}{*}{$\begin{array}{l}\text { Mainly animals (TL 2,8 and up) } \\
\text { - B. boops - Sardina } \\
\text { pilchardus } \\
\quad \text { Algae- Copepods }\end{array}$} & \\
\hline S. dumerili & & 4.21 \\
\hline B. boops & & 2.92 \\
\hline Benthic Algae & & 1 \\
\hline c) & \multirow{6}{*}{$\begin{array}{l}\text { mainly animals (troph. } 2.8 \text { and } \\
\text { up) Zoobenthos- Nekton- S. } \\
\text { porcus } \\
\text { mainly animals (troph. } 2.8 \text { and } \\
\text { up)- G. niger } \\
\text { mainly animals (troph. } 2.8 \text { and } \\
\text { up) }\end{array}$} & \\
\hline Z. faber & & 4.50 \\
\hline S. porcus & & 3.77 \\
\hline G. niger & & 3.32 \\
\hline Copepoda & & $? ? ?$ \\
\hline Benthic algae & & 1 \\
\hline d) & \multirow{4}{*}{$\begin{array}{l}\text { mainly animals (troph. } 2.8 \text { and } \\
\text { up) - P. lividus } \\
\text { Algae }\end{array}$} & \\
\hline D. sargus sargus & & 3.17 \\
\hline P. lividus & & 2.03 \\
\hline Benthic algae & & 1 \\
\hline e) & \multirow{4}{*}{$\begin{array}{l}\text { mainly animals (troph. } 2.8 \text { and } \\
\text { up) - B. salpa } \\
\text { Plants- Bnthic algae and } \\
\text { Posidonia oceanica }\end{array}$} & \\
\hline E. marginatus & & 3.73 \\
\hline B. salpa & & 2.00 \\
\hline Posidonia oceanica & & 1 \\
\hline
\end{tabular}

In addition, measurements of mercury concentrations in water suffer from a similar lack of breadth and depth, as they fail to cover all years, appear only sporadically within each eco-region, and are often concentrated in the North-Western Mediterranean.

Despite these concerns, we observed a very clear bioaccumulation trend in 1999, the only year where comprehensive information on both methylmercury concentrations in water and biota was available (Figure 2).

\section{Conclusion}

Our exercise on mercury bioaccumulation in Mediterranean biota showed a very clear trend when data was available. Despite a wide variety of information, meaningful analysis was only possible when the data was more comprehensive; for only one year, for only one eco-region.

This makes any assessment very uncertain, especially in the South-Eastern part of the Mediterranean. 


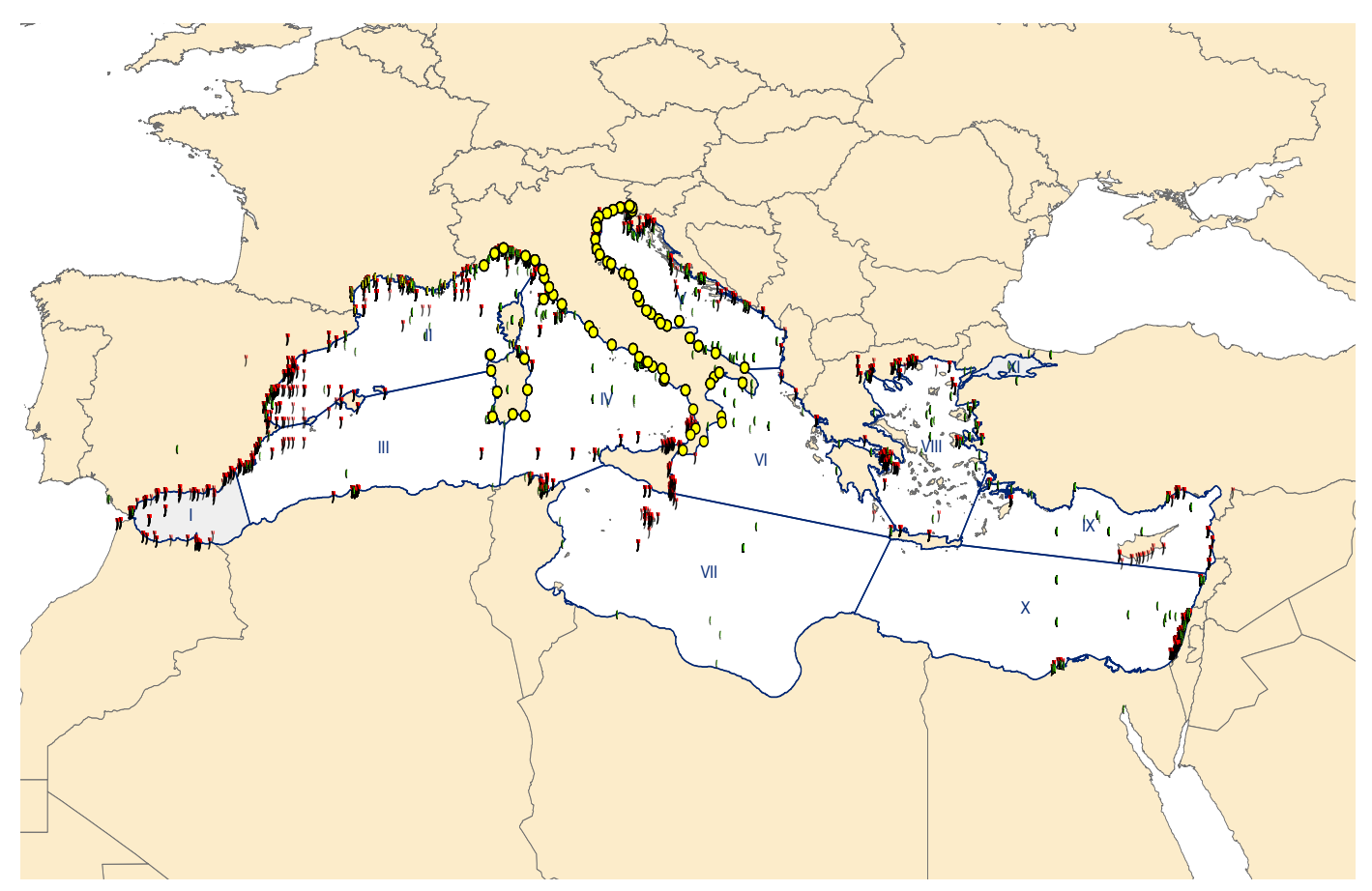

Fig. 1. Dataset on mercury concentration in biota used for the assessment: MEDPOL (red squares), MLI (green dots) and RNO+SIDIMAR (yellow dots).

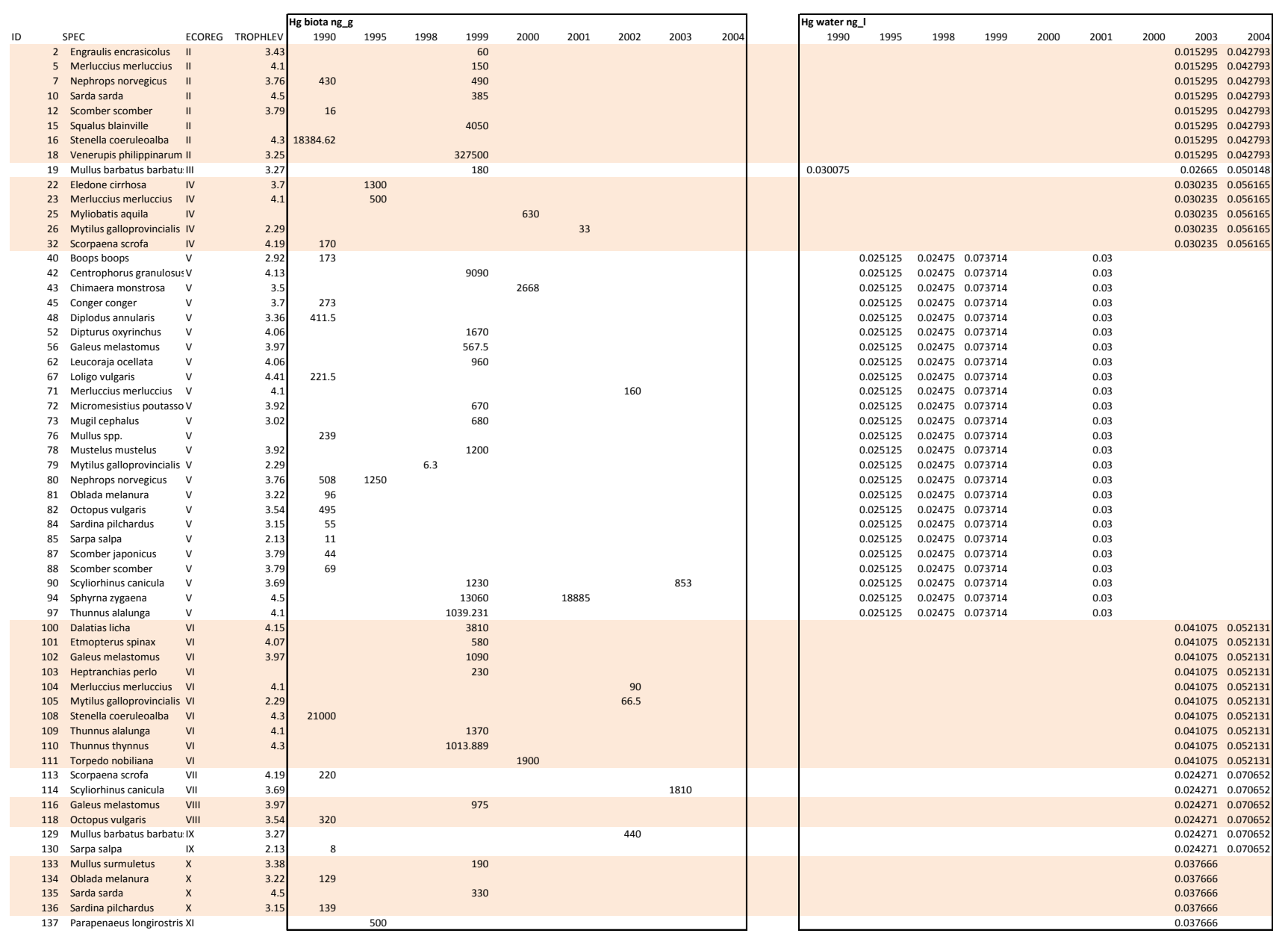

Table 2. Methylmercury concentration in biota (left) and water (right) in different Mediterranean eco-regions for the available years. Concentrations in water were averaged for each eco-region on the basis of scattered sampling points. 


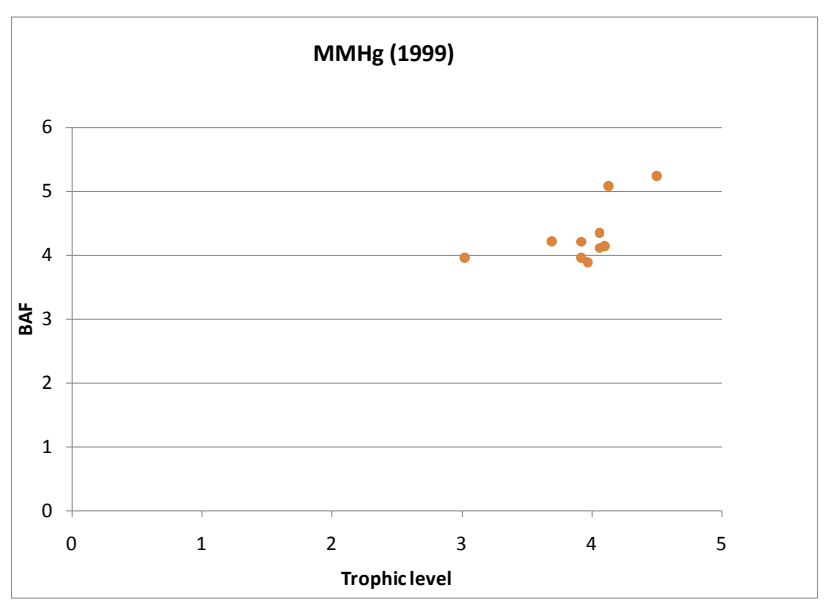

Fig. 2. BAF for different trophic levels in the Adriatic (V) marine eco-region of the Mediterranean. Data from the year 1999.

Our analysis suggests a number of areas for future research. Future studies ought:

- to implement, where possible, a trophic net when doing monitoring campaigns;

- to enhance discovery of information for South-Eastern Mediterranean countries, and to build capacity for conducting such research into large international initiatives like GEOSS;

- to improve regional monitoring programs (e.g. those maintained by the Mediterranean Action Plan);

- to better test BAF applicability at local and marine levels.

To obtain an accurate understanding of mercury's environmental presence in biota, it is very important to have information that correctly indentifies the source of the fish. As information on mercury concentrations in fish has been collected primarily for human-health related purposes, we want to acknowledge that the fish data we reference does not accurately represent mercury concentrations in the fish of a particular Mediterranean region. The majority of fish consumed in these regions are either from aquaculture facilities and/or are imported from other regions.

In the following months, we will produce a good overview of mercury in Mediterranean fisheries, with noteworthy differences between aquaculture-produced fish and wild-caught fish in the Mediterranean Basin. When that study is completed, we plan to revisit this question and re-evaluate the data collected in the present work.

\section{Acknowledgements}

The authors would like to express their gratitude for financial support provided by the GMOS Project (FP7-ENV-2010 No. 265113) and the KnowSeas Project (FP7-ENV-2008-1 No. 226675).

\section{References}

Bernhard M., Renzoni A., 1977. Mercury concentration in Mediterranean marine organisms and their environment: natural and anthropogenic origin. Thalassia Jugosl., 13: 265-300.

Chen C., Amirbahman A., Fisher N., Harding G., Lamborg C.,Nacci D., Taylor D., 2008. Methylmercury in marine ecosystems: spatial patterns and processes of production, bioaccumulation, and biomagnification. Ecohealth, 5(4): 399-408.

Harmelin-Vivien M., Cossa D., Crochet S., Banaru D., Letourneur Y., Mellon-Duval C., 2009. Difference of mercury bioaccumulation in red mullets from the north-western Mediterranean and Black seas. Mar Pollut Bull 58(5): 679-685.

Law R., Hanke G., Angelidis M., Batty J., Bignert A., Dachs J., Davies I., Denga Y., Duffek A., Herut B., Hylland K., Lepom P., Leonards P., Mehtonen J., Piha H., Roose P., Tronczynski J., Velikova V., Vethaak D., 2010. Marine Strategy Framework Directive, Task Group 8 Report, Contaminants and pollution effects. (Piha H., Editor). EUR - Scientific and Technical Research series, JRC and ICES.

Sanborn J.R., Brodberg R.K., 2006. Evaluation of bioaccumulation factors and translators for methylmercury. California Environmental Protection Agency.

Thibaud Y., 1971. Teneur en mercure dans quelques poissons de consommation courante. Sci. Pêche., 209: 1-10. 